\title{
Evaluación del espectro de la nebulosa planetaria NGC 1501
}

\author{
Eduardo-Enrique Rodas-Quito ${ }^{1, *}$, Hugo-Heomar Ramos-Hernández ${ }^{2,+}$ \\ ${ }^{1}$ Máster, Departamento de Arqueoastronomía y Astronomía Cultural de la UNAH \\ ${ }^{2}$ Ingeniero Industrial, Departamento de Astronomía y Astrofísica de la UNAH \\ DOI: https://doi.org/10.5377/ce.v11i2.8676
}

\begin{abstract}
RESUMEN
Se realizó el análisis del espectro de la nebulosa designada en el New General Catalog con el número 1501 (NGC1501), utilizando como herramienta de análisis el software Image Reduction and Analysis Facility (IRAF), con el cual se realizaron diversos tratamientos al espectro del objeto antes mencionado. La estrella de referencia utilizada para la calibración del espectro de NGC1501 es la G191B2B. Como resultado final, se obtuvieron datos de algunos de los elementos presentes en la nebulosa planetaria estudiada, una estimación de la cantidad de polvo interestelar presente en la línea de visión Tierra nebulosa, la densidad electrónica en la nebulosa y la temperatura electrónica del gas que la compone.
\end{abstract}

Palabras clave: espectroscopía, nebulosa planetaria, evolución estelar.

\begin{abstract}
The spectrum analysis of the nebula designated in the New General Catalog with number 1501 (NGC1501) was performed, using the Image Reduction and Analysis Facility (IRAF) software as an analysis tool, with which several treatments were carried out to the spectrum of the object aforementioned. The reference star used for the NGC1501 spectrum calibration is G191B2B. As a final result, data on some of the elements present in the nebula, an estimation of the quantity of interstellar dust in the line of sight Earth-nebula, electronic density of the nebula and electronic temperature of the gas that makes up the nebula were obtained.
\end{abstract}

Keywords: spectroscopy, planetary nebula, stellar evolution.

\section{Introducción}

En astronomía, el análisis de la radiación que emiten o reflejan los cuerpos astronómicos ha probado ser una técnica muy útil para conocer y entender las composiciones de los mismos, así como los diversos procesos físicos que los originan y que se llevan a cabo en dichos cuerpos astronómicos, ya sea al interior o en la superficie de los mismos. Esta radiación tendrá diversas características según la cantidad de energía que contiene (o longitud de la onda con dicha energía), lo cual se aprecia al momento de captarla y registrarla en los instrumentos que se utilizan. Estos registros que se obtienen tienen el nombre de espectro, que en un principio se refirió únicamente a los colores del arcoíris, obtenidos cuando un haz de luz se hace pasar a través de un prisma. Sin embargo, al descubrirse que hay radiaciones que están mas allá de

*eduardo.rodas@unah.edu.hn

†hugo.ramos@unah.edu.hn 
la luz visible por parte de William Herschel, se utilizó para designar a todas las longitudes de onda que puede tener la radiación electromagnética. Dado que las características de la energía transportada por la radiación electromagnética dependen de los diversos procesos físicos que la originaron (o la removieron), el análisis de esta radiación sirve como una medición indirecta de dichos procesos, de ahí la importancia de las técnicas para el análisis de las mismas. Cuanto más perfeccionada sea la técnica, mejores datos se pueden extraer de los espectros estudiados y se pueden deducir de forma más precisa cuáles fueron los procesos que la originaron o removieron y por tanto, se puede tener una mejor idea de las propiedades y características de los cuerpos astronómicos en donde se llevan a cabo estos procesos. Es de esta forma que se realizó el análisis del espectro del objeto NGC1501 que, según la literatura consultada, es una nebulosa planetaria ubicada aproximadamente a $1.30 \mathrm{kpc}$ de la Tierra (Sabbadin et al., 2000). El espectro utilizado se obtuvo a partir de imágenes tomadas con el telescopio de $1.22 \mathrm{mts}$, del Observatorio Aciago, en Italia. El software de análisis que se utilizó es el IRAF, de uso muy extendido para reducción y presentación de datos obtenidos con instrumentos astronómicos. En la sección 2 se describen los datos y la metodología utilizada para su reducción, así como el análisis del espectro de la nebulosa NGC 1501, describiendo el origen y tipo de imágenes con que se trabajó, detallando los comandos del software de procesamiento de imágenes que se utilizaron en cada una de las etapas, así como el proceso de extracción e identificación de líneas de emisión. En la sección 3 se describen las características de las líneas identificadas en el espectro obtenido luego de la reducción, identificando diversos elementos químicos, y se les diferencia de aquellas que muy probablemente son parte del ruido. En la sección 4 se analizan por elemento los diversos procesos que pudieron dar origen a dichas líneas de emisión. Se termina en la sección 5 donde se dan las conclusiones que surgen del análisis de la sección anterior.

\section{Metodología y obtención de datos}

\subsection{Origen de los datos}

Se partió de imágenes obtenidas con el telescopio del observatorio Aciago, telescopio de $1.22 \mathrm{mts}$. Se utilizó un set completo de imágenes, que incluían dos imágenes del objeto a estudiar, una imagen de la estrella de referencia, dos pares de imágenes de las lámparas usadas como referencia para calibrar las líneas de los espectros y 5 imágenes correspondientes al flat, que sirvieron para remover imperfecciones en las imágenes causadas por el telescopio.

\subsection{Reducción de los datos}

Para esto se utilizó el software Image Reduction and Analysis Facility (IRAF), que es de acceso libre (Tody, 1986) y se puede obtener del sitio web www. iraf . net. Con el mismo se realizaron los siguientes procesos:

- En el tratamiento de imágenes astronómicas, normalmente se parte del paso llamado "corrección por Bias", en el cual se hace una corrección para eliminar luz de "ruido" que hace que las imágenes parezcan tener una luminosidad mayor a la que realmente se podría captar, lo cual es debido a la electricidad que circula por el detector mientras está operando. Dado que para este trabajo no se contaba con dichas imágenes, se hizo la corrección valiéndose de una sección de las imágenes que no sufrió exposición (las últimas 50 columnas de pixeles a la derecha de las imágenes), por tanto permaneciendo oscuras y únicamente registrando la energía de la electricidad del detector. Esta área es la que se conoce como el "overscan" y con ayuda de la rutina images.imstatistics se obtuvo para cada una de las imágenes el valor de bias a restar en el proceso de corrección. Posteriormente 
se hizo la corrección por bias con el task images . imutil. imarith, aplicado a todas las imágenes con que se contaba.

- Se generó una sola imagen de flat o masterflat, a partir de las 5 con que se contaba, por medio del task images.immatch.imcombine. Posteriormente se normaliza la imagen del flat, con el task noao.twodspec. longslit.response, y se hace corrección de las imágenes del objeto bajo estudio y de la estrella de referencia por flat, utilizando para esto el task images . imutil. imarith, dividiendo las imágenes del objeto bajo estudio y de la estrella de referencia entre el masterflat normalizado (ver figura 1 y figura 2)

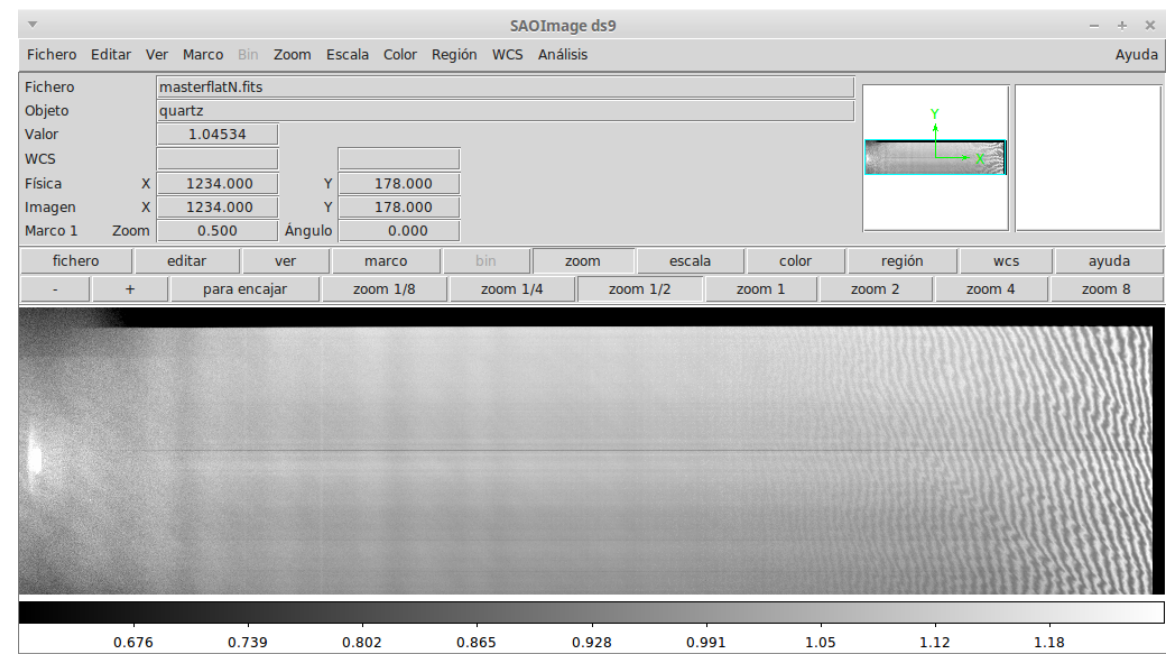

Figura 1: Procesando imágenes de lámparas combinadas.

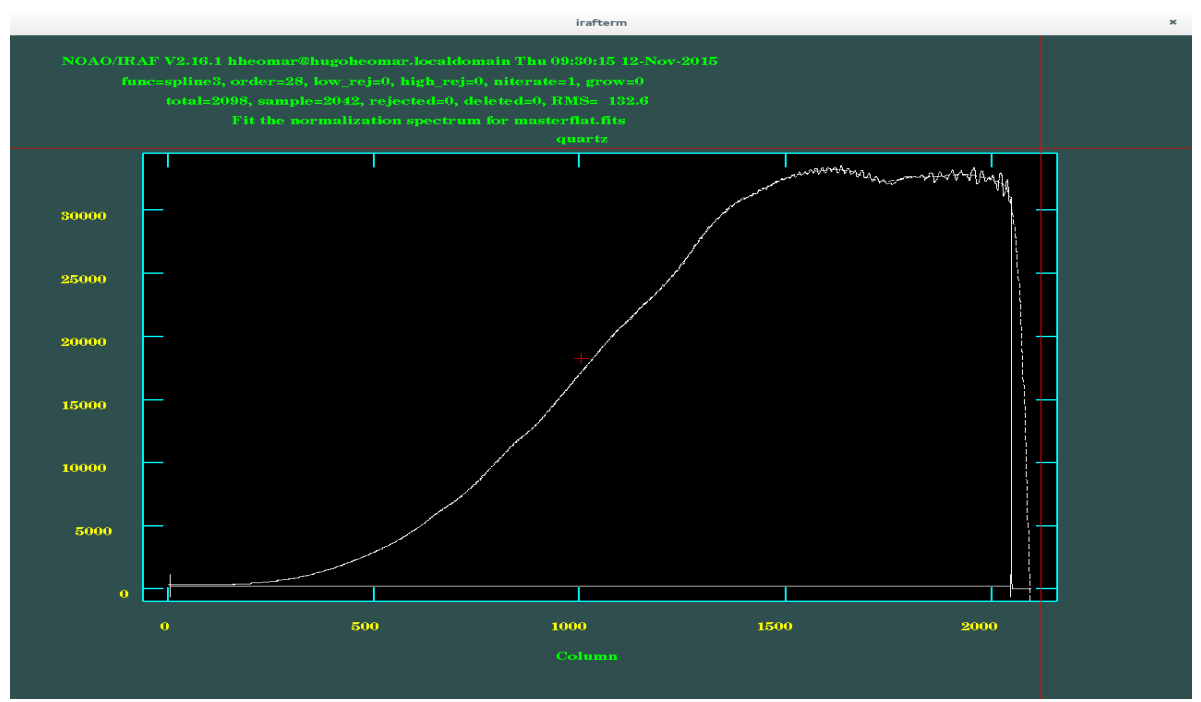

Figura 2: Imagen Normalización del masterflat ajustándolo con un polinomio de orden 28.

- Calibración de las líneas de emisión de las lámparas que se usarán como referencia en los siguientes pasos:

- Suma de las imágenes de emisión de lámparas de Mercurio-Argón y de Neón, siempre con 
images.imutil.imarith

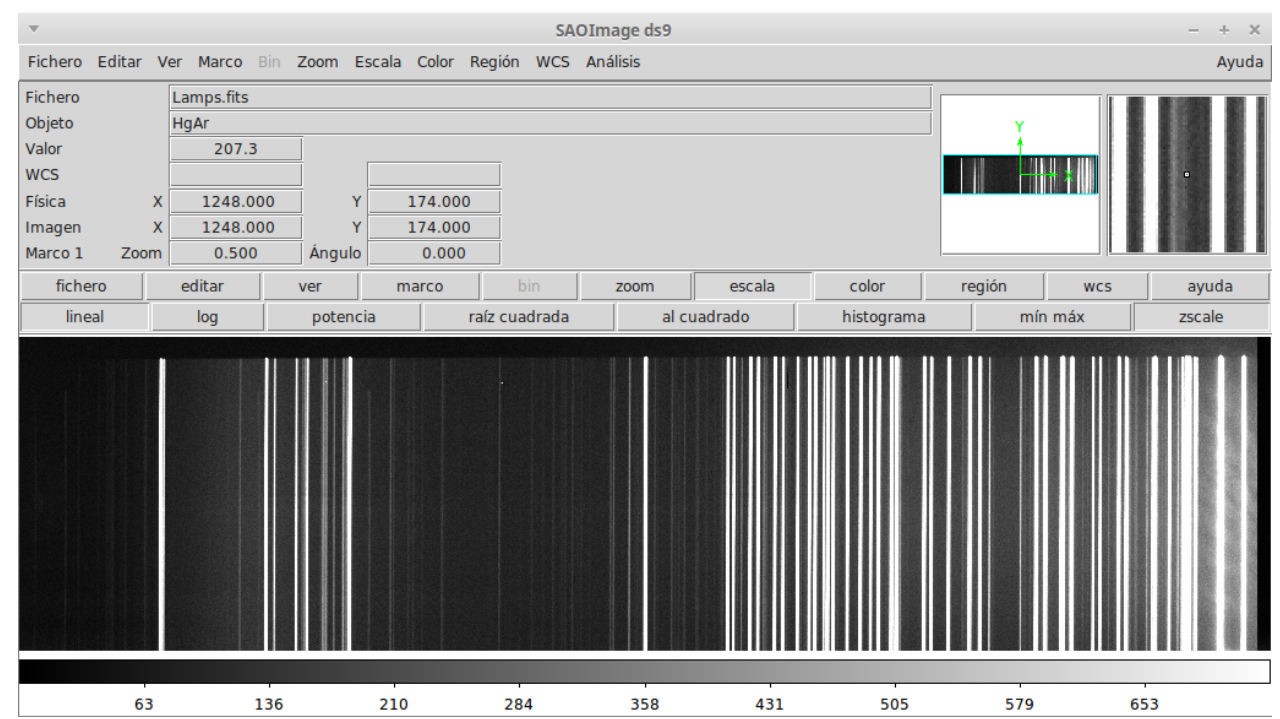

Figura 3: Imagen suma de lámparas $\mathrm{HgArNe}$.

- Identificación de las líneas de emisión de la imagen de las lámparas basándose en las referencias (Fritz, 2015), utilizando el task noao . twodspec . longslit . ident ify y ajustando las coordenadas dentro de dichas imágenes a modo que se logre identificar la longitud de onda por medio de la coordenada $x$ dentro de la imagen, finalizando con una reidentificación de las líneas, con el task noao.twodspec. longslit.reidentify y con el que se crea un mapa en 2 dimensiones de las distorsiones por dispersión.

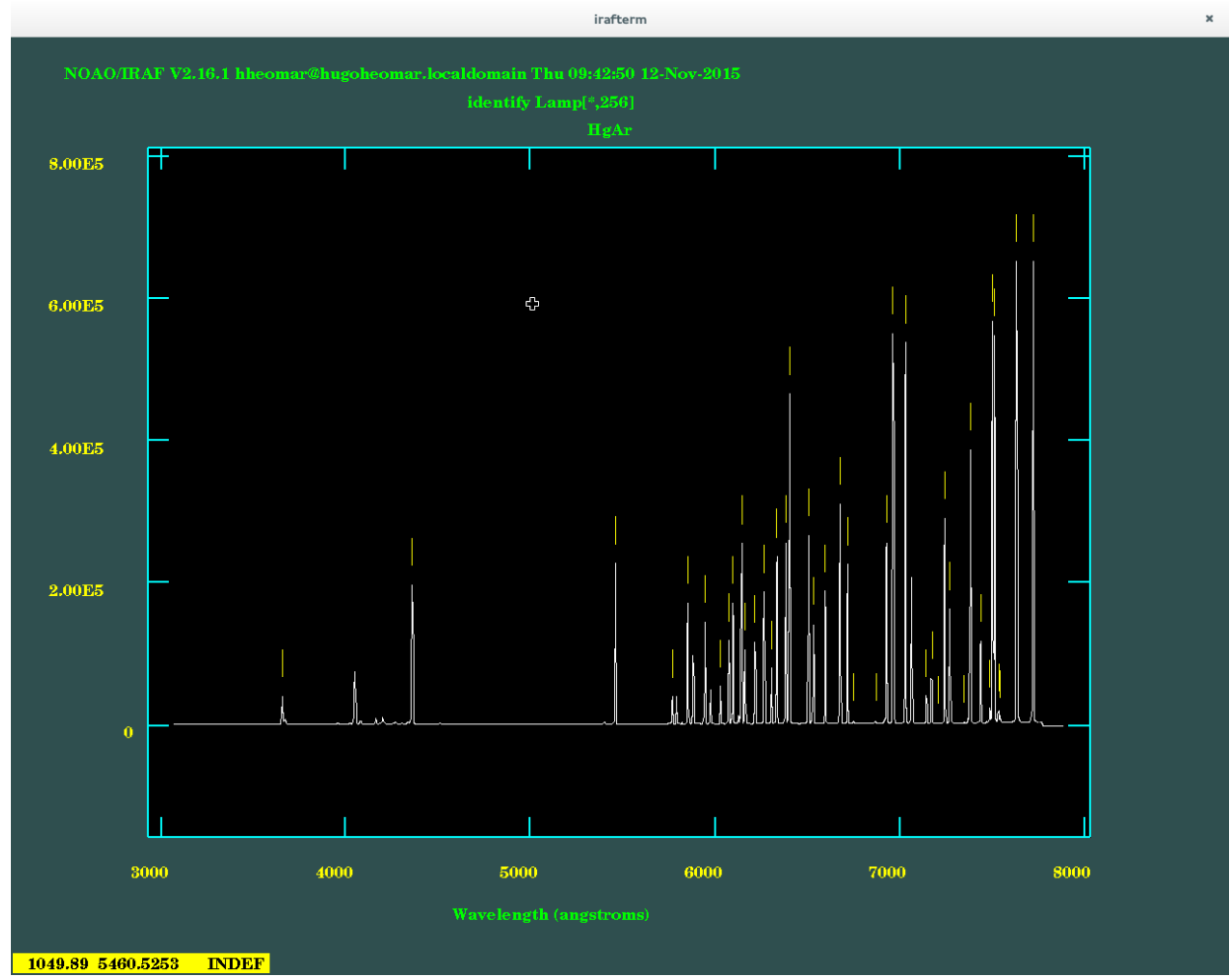

Figura 4: Imagen de los picos del espectro. 
- Re-ajuste de las coordenadas del rango de longitudes de onda medidas en el paso anterior a la imagen de las lámparas, con el task noao.twodspec.longslit.fitcoord

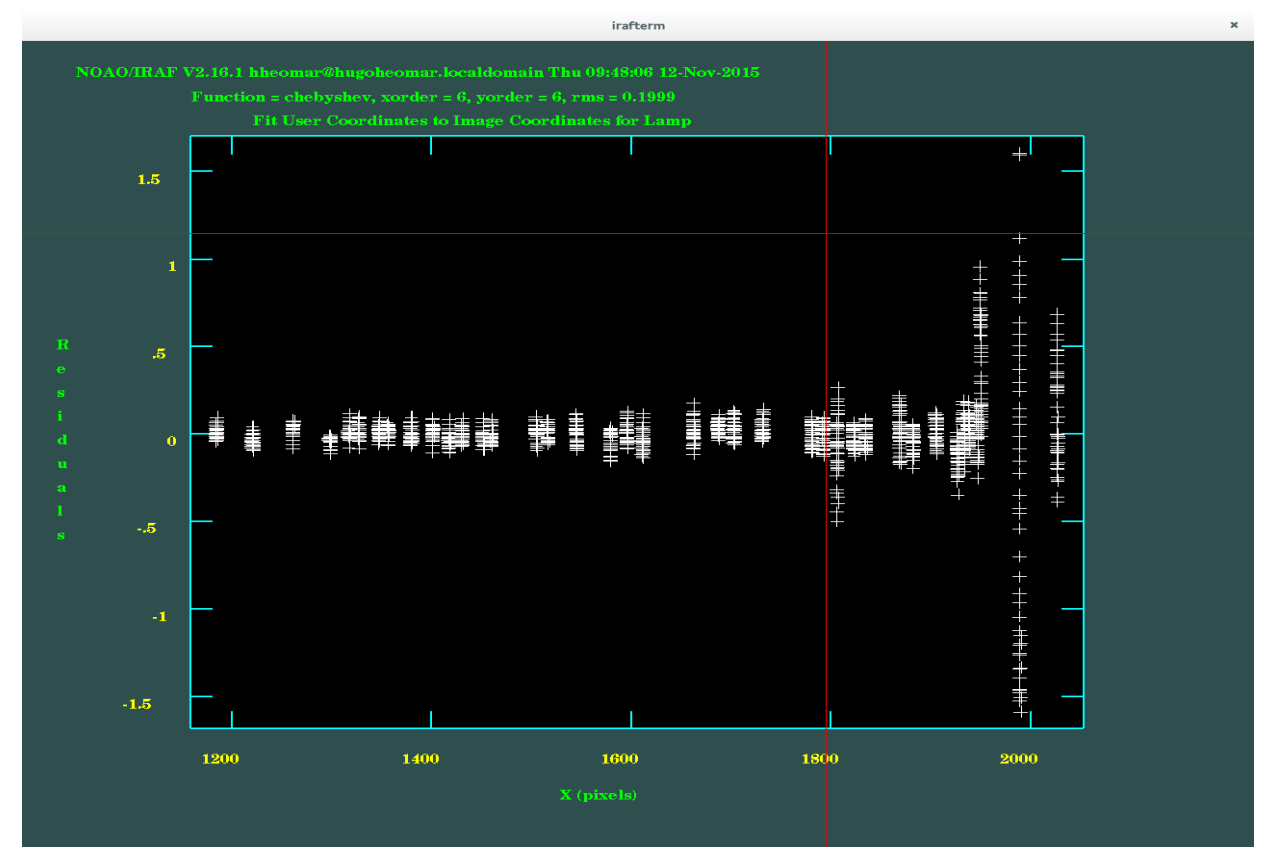

Figura 5: Residuales obtenidos al realizar los ajustes de coordenadas.

- Asignación de las coordenadas a las diferentes longitudes de onda en la imagen de las líneas de emisión de las lámparas con el task noao. twodspec. longslit.transform (ver figura 6)

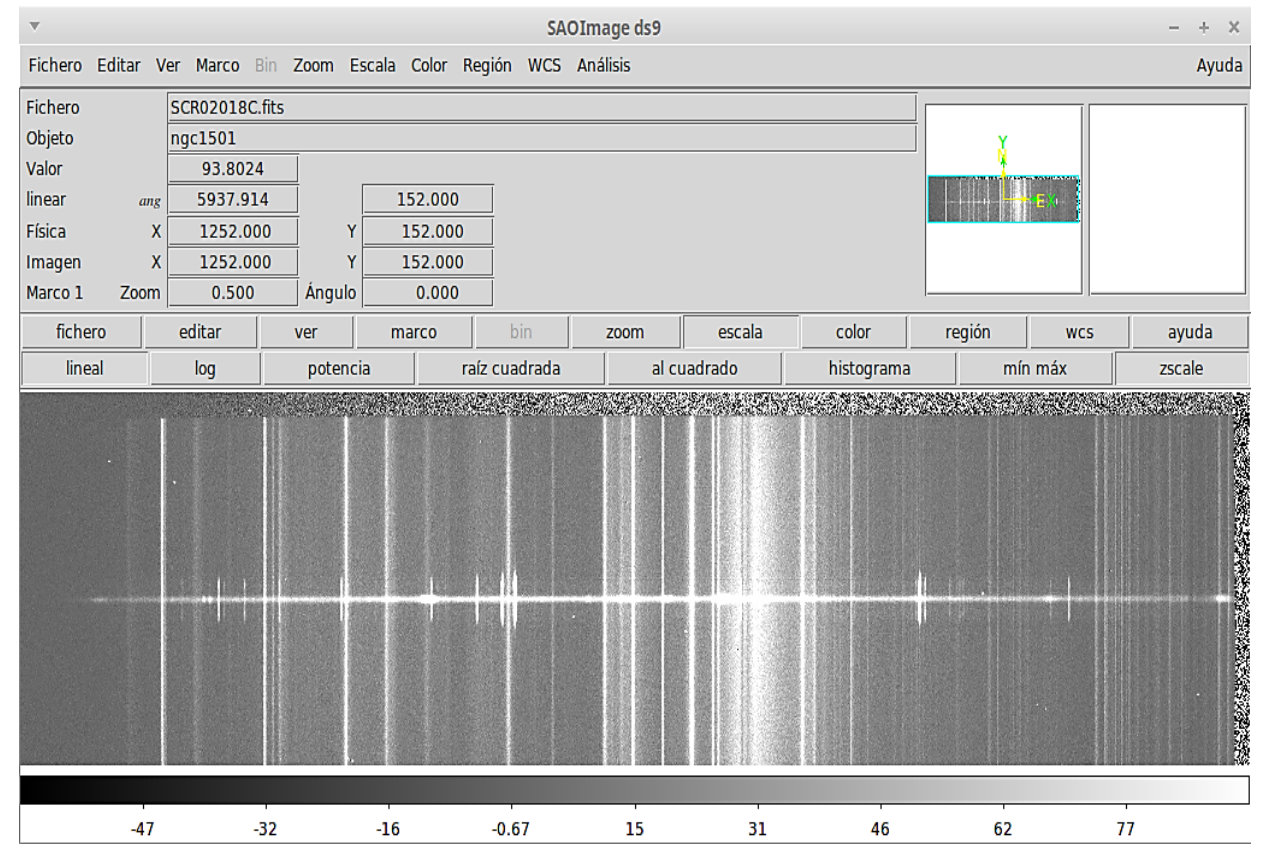

Figura 6: Espectro de NGC 1501 con sus líneas espectrales ya identificadas y a las que se les han asignado sus coordenadas. 
- Extracción del espectro del objeto y estrella de referencia utilizando el task apextract.apall con el que se evalúa de forma gráfica el rango de longitudes de onda a extraer, tanto para el pico en el flujo, el centro de la longitud de onda y se marca también el valor promedio del fondo de radiación.

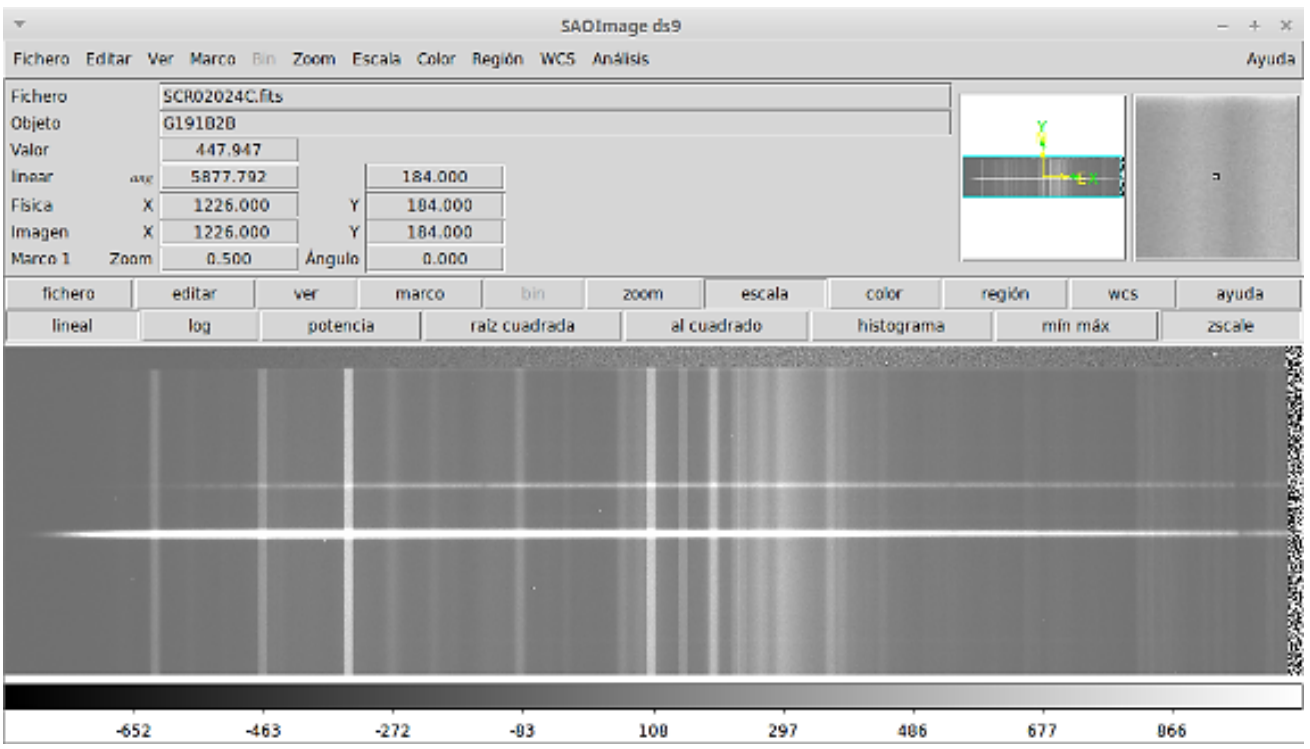

Figura 7: Espectro de la estrella de referencia G191B2B con sus líneas espectrales ya identificadas y a las que se les han asignado sus coordenadas.

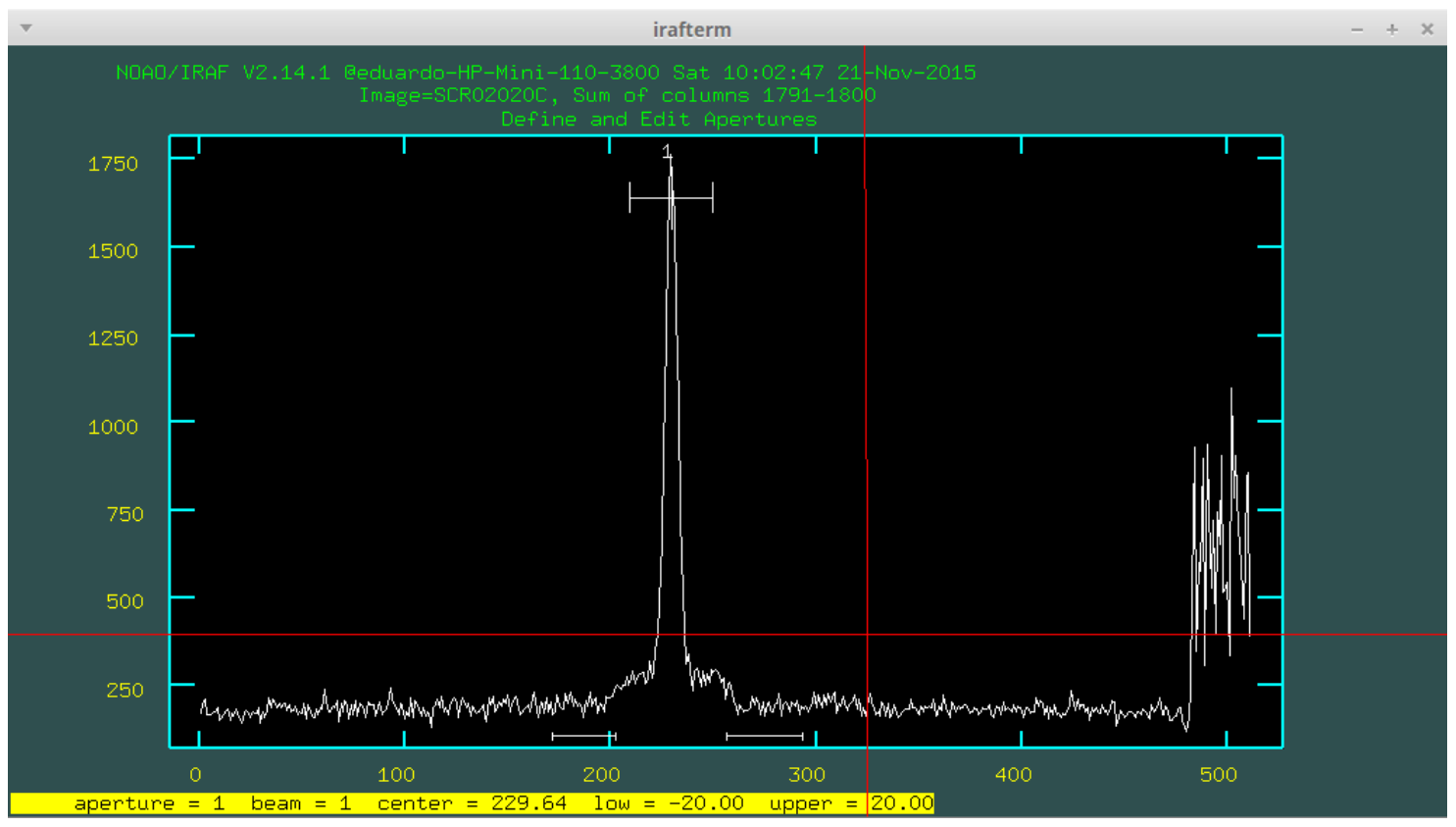

Figura 8: Selección de rangos para la extracción del espectro. 
- Calibración del flujo en el espectro del objeto, utilizando el flujo de la estrella de referencia como guía, para lo cual se hace como sigue:

- Identificación de la estrella estándar, utilizando el task noao . onedspec. standard, con el que se identifica la estrella utilizada de referencia de acuerdo a la base de datos del IRAF.

- Se calcula la función de sensibilidad comparando el espectro de la estrella en la base de datos con el espectro con que se cuenta de dicha estrella según la observación realizada (ver figura 9).

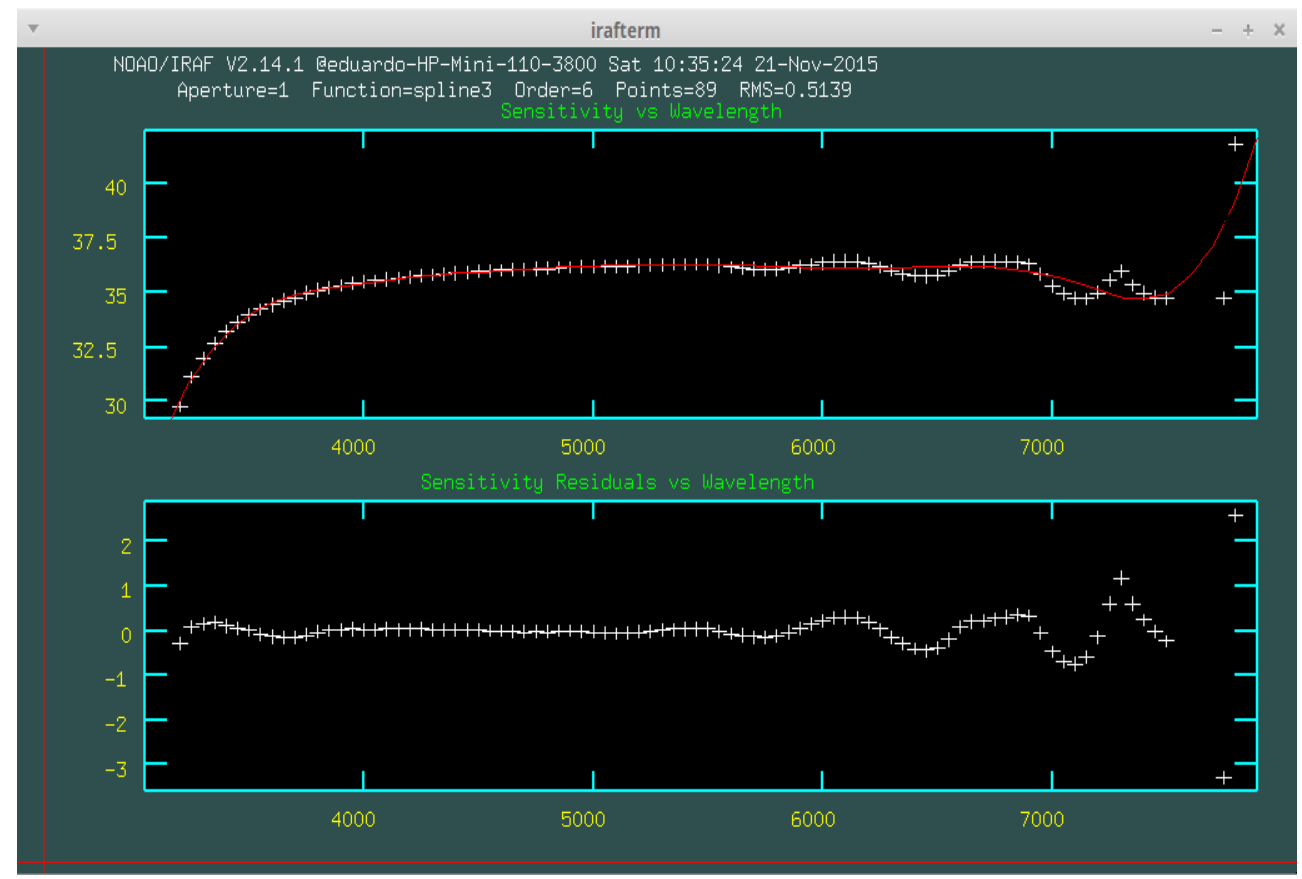

Figura 9: Ajuste de la función de sensibilidad en varias bandas.

- Calibración del flujo del espectro del objeto que se estudiará, utilizando el task noao . onedspec. calibrate con el que finalmente se relacionan el espectro de la estrella con el del objeto bajo estudio, sensibilizado. 


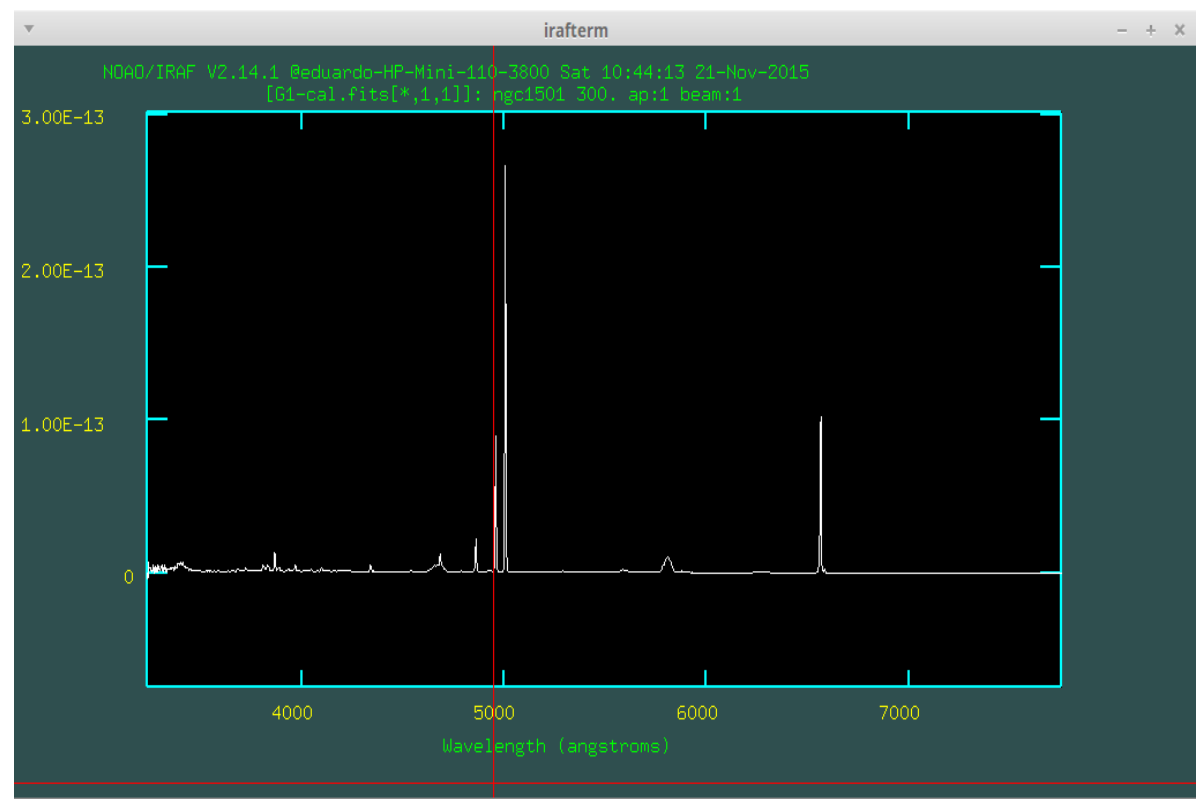

Figura 10: Espectro final del objeto, calibrado su flujo y ajustadas sus longitudes de onda, listo para la identificación de los elementos responsables de las líneas de emisión y/o absorción.

\subsection{Problemas encontrados en la reducción del espectro}

Durante el seguimiento de este proceso, se encontraron una serie de problemas que se resolvieron a medida que se iba adquiriendo familiaridad con la operación del IRAF. Entre estos problemas tenemos:

- El espectro obtenido luego de la aplicación del task noao.twodspec. longslit.transform no tenía las características esperadas de una imagen de espectro, sino que se generaba una imagen distorsionada, en la que no se podían identificar líneas de ningún tipo. Este problema se resolvió al repetir el procesamiento de las imágenes desde un principio, poniendo especial cuidado en la etapa de generación de masterflat y de la división de las diferentes imágenes (objeto, estrella de referencia y lámparas) entre este masteflat que se generó. Una posible causa del problema se describe en el siguiente inciso.

- La identificación de las líneas de emisión en los espectros de las lámparas probó ser una etapa especialmente desafiante, ya que tomó un tiempo la correcta identificación de los patrones de líneas en la imagen de referencia utilizada y asociarlas a los patrones observados en la pantalla de la computadora. Una vez logrado esto, el reto estaba en la comparación por parte de la computadora de las líneas que se identificaron con las que tenía en su base de datos.

A veces ocurría que las líneas a las que se les asignó una longitud de onda determinada, el software lo cambiaba por el valor de otra línea de emisión en la base de datos, lo que provocaba que no tuviera el espectro la escala correcta en longitudes de onda. Por este motivo, se realizó esta etapa varias veces y de hecho, se presume que este paso fue uno de los causantes del problema encontrado en el inciso anterior. La resolución de este problema se logró al identificar cuidadosamente solo las líneas más intensas en el espectro de las lámparas y que al mismo tiempo estuvieran bien distribuidas a lo largo de todo el espectro. De esta manera, pareciera que el software tenía menos problemas en asociar las líneas identificadas por el usuario con la información en la base de datos. Superados estos problemas, el proceso de extracción y 
calibración del flujo del espectro fue realmente fluido y solo requiere del cuidado a los detalles en cada uno de los pasos necesarios para extraer el espectro del objeto a estudiar.

\section{Mediciones de las líneas}

Se procedió a evaluar las líneas (ya fueran de absorción o de emisión) que estaban presentes en el espectro obtenido. Para la nebulosa NGC1501, sabemos que corresponde a una nebulosa planetaria (ver figura 11), por lo que sería de esperar obtener un espectro con líneas de emisión únicamente, dado que este tipo de objetos no generan su propia energía, sino que reflejan o emiten según la energía que absorben de estrellas cercanas, en este caso, el remanente de la estrella que originó dicha nebulosa. En el espectro obtenido se observaron además de las líneas de emisión, líneas de ruido a los extremos.

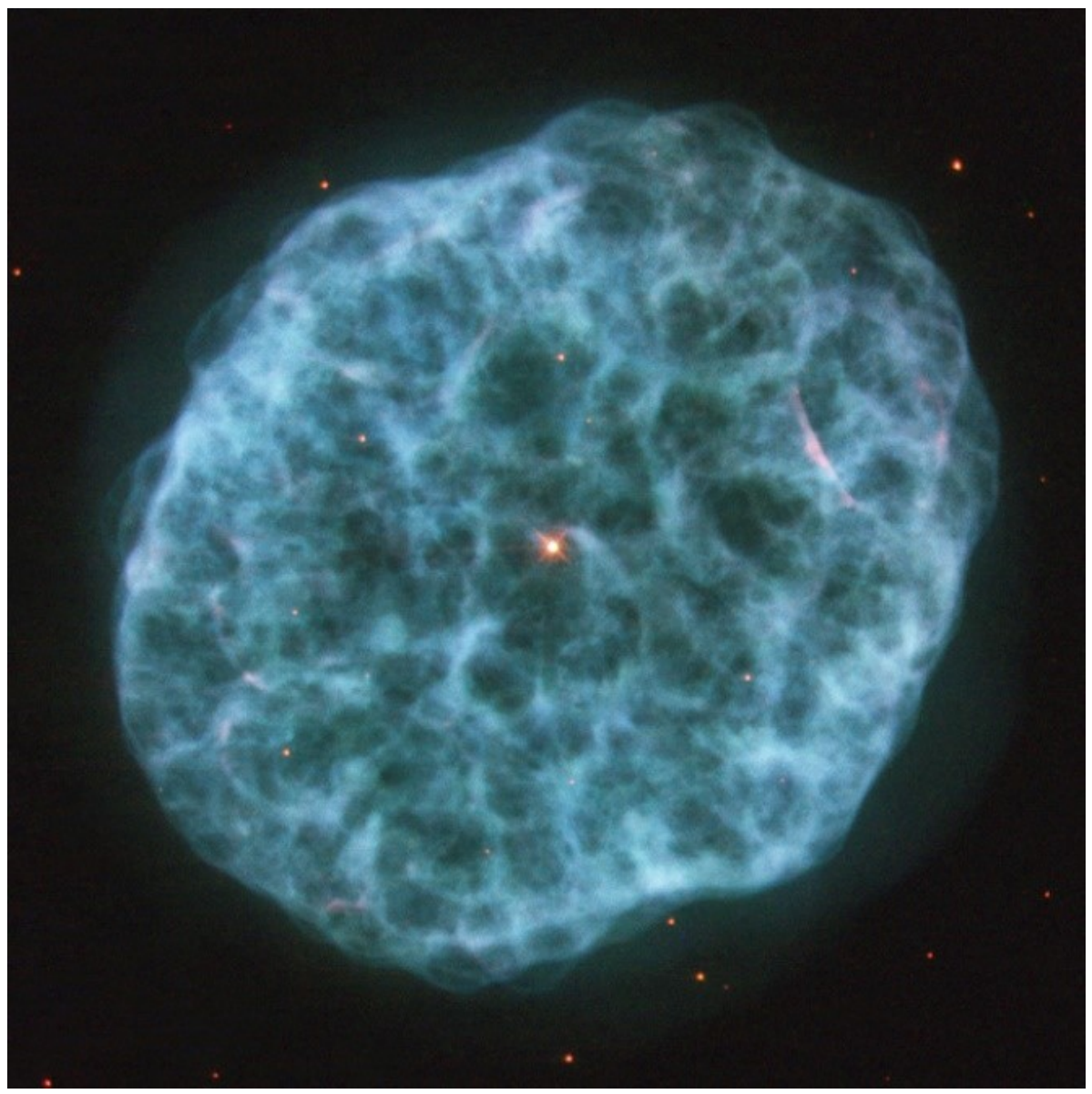

Figura 11: Nebulosa planetaria NGC 1501, tal como la fotografió el Telescopio Espacial Hubble (Tomado de Wikipedia, bajo la licencia Creative Commons Attribution 2.0 Generic).

Con el programa IRAF se pueden realizar acercamientos a secciones que sean de interés en la imagen del espectro, por lo que para efectos de una mejor visualización, se hizo un acercamiento a la parte de interés en el espectro, recortando el ruido en los extremos, como se puede ver en la figura 10. 


\section{Resultados y discusión}

Las líneas de emisión que se observaron en el espectro se presentan en la tabla 1.

Tabla 1: Líneas de emisión observadas en el espectro de NGC 1501

\begin{tabular}{|c|c|c|c|c|c|}
\hline $\mathrm{N}^{\circ}$ & $\begin{array}{l}\text { Longitud de onda } \\
\qquad(\AA)\end{array}$ & $\begin{array}{c}\text { Flux } \times 10^{14} \\
\left(\text { Erg cm }{ }^{-2} \mathrm{~s}^{-2}\right)\end{array}$ & $\begin{array}{l}\text { Continuum } \times 10^{14} \\
\left(\text { Erg cm } \mathrm{cm}^{-2} \mathrm{~s}^{-2}\right)\end{array}$ & $\begin{array}{c}\text { Ancho equivalente }{ }^{* *} \\
(\AA)\end{array}$ & Observaciones \\
\hline 1 & 3376.310 & 1.53 & 9.5 & 6.609 & Deblending* \\
\hline 2 & 3383.280 & 1.54 & 7.75 & 6.765 & Deblending* \\
\hline 3 & 3392.500 & 5.07 & 9.5 & 22.65 & Deblending* \\
\hline 4 & 3404.230 & 4.37 & 9.25 & 19.97 & Deblending* \\
\hline 5 & 3413.440 & 3.85 & 6.00 & 17.97 & Deblending* \\
\hline 6 & 3420.420 & 2.67 & 7.5 & 12.63 & Deblending* \\
\hline 7 & 3429.630 & 1.92 & 3.0 & 9.271 & Deblending* \\
\hline 8 & 3441.350 & 1.25 & 2.13 & 6.212 & Deblending* \\
\hline 9 & 3690.433 & 1.114 & 0.1868 & 5.6723 & \\
\hline 10 & 3727.177 & 1.085 & 0.2018 & 5.3744 & \\
\hline 11 & 3796.528 & 1.512 & 0.1879 & 8.0264 & \\
\hline 12 & 3810.970 & 3.74 & & 18.95 & Deblending* \\
\hline 13 & 3835.940 & 4.36 & & 22.77 & Deblending* \\
\hline 14 & 3868.731 & 7.707 & 0.1962 & 39.0232 & \\
\hline 15 & 3889.090 & 1.047 & 0.2043 & 5.1249 & \\
\hline 16 & 3921.030 & 0.257 & & 1.486 & \\
\hline 17 & 3927.770 & 0.479 & & 2.733 & \\
\hline 18 & 3936.340 & 0.449 & & 2.525 & \\
\hline 19 & 3944.580 & 0.403 & & 2.236 & \\
\hline 20 & 4042.417 & 0.249 & 0.151 & 1.637 & \\
\hline 21 & 4047.850 & 0.149 & & 0.945 & \\
\hline 22 & 4054.570 & 0.18 & & 1.148 & \\
\hline 23 & 4101.750 & 2.003 & 0.1747 & 11.5112 & \\
\hline 24 & 4340.132 & 2.93 & 0.1252 & 23.5409 & \\
\hline 25 & 4361.601 & 0.7775 & 0.1283 & 48.94 & \\
\hline 26 & 4658.980 & 7.26 & & 43.55 & Deblending* \\
\hline 27 & 4686.030 & 6.12 & & 90.52 & Deblending* \\
\hline 28 & 4861.344 & 14.84 & 0.132 & 75.6657 & \\
\hline 29 & 4958.994 & 58.42 & 0.236 & 246.793 & \\
\hline 30 & 5006.945 & 181.9 & 0.167 & 1087.499 & \\
\hline 31 & 5808.278 & 36.65 & 0.1016 & 360.855 & \\
\hline 32 & 6548.620 & 0.786 & & 134 & Deblending* \\
\hline 33 & 6563.550 & 70.1 & & 12000 & Deblending* \\
\hline 34 & 6581.950 & 1.95 & & 332.8 & \\
\hline 35 & 6716.360 & 0.0155 & & 5.387 & \\
\hline 36 & 6730.800 & 0.0181 & & 6.184 & \\
\hline 37 & 6803.511 & 0.0618 & 0.00281 & 26.6705 & \\
\hline 38 & 6907.750 & 0.0347 & & 10.08 & \\
\hline 39 & 6936.290 & 0.517 & & 143.1 & \\
\hline \multicolumn{6}{|c|}{$\begin{array}{l}\text { *Fue necesario ejecutar el módulo de "deblending" en el software IRAF para poder diferenciar } \\
\text { estas líneas, que en un principio parecían formar una sola línea de emisión muy ancha } \\
{ }^{* * T o d o s ~ l o s ~ v a l o r e s ~ d e l ~ a n c h o ~ e q u i v a l e n t e ~ s e ~ m u l t i p l i c a n ~ p o r ~}-1\end{array}$} \\
\hline
\end{tabular}

Se muestran en la tabla 1 las longitudes de onda en donde se encontraron líneas de emisión, cuyas longitudes de onda se muestran en la segunda columna, las intensidades (dadas por el valor del flujo, en unidades de ergios $\mathrm{cm}^{-2} \mathrm{~s}^{-1}$ ) aparecen en la segunda columna, el valor de flujo del continuo correspondiente a donde se mide cada línea de emisión está en la tercera columna (si es que estaba disponible), el ancho equivalente en la penúltima columna y observaciones en la última columna (tales como si fue necesario usar deblending para obtener los datos de varias líneas de emisión si estaban muy cerca entre 
sí, como se muestra en las figuras 12 y 13 para las líneas de emisión 1 al 8 y las líneas 12 y 13 de la tabla $1)$.

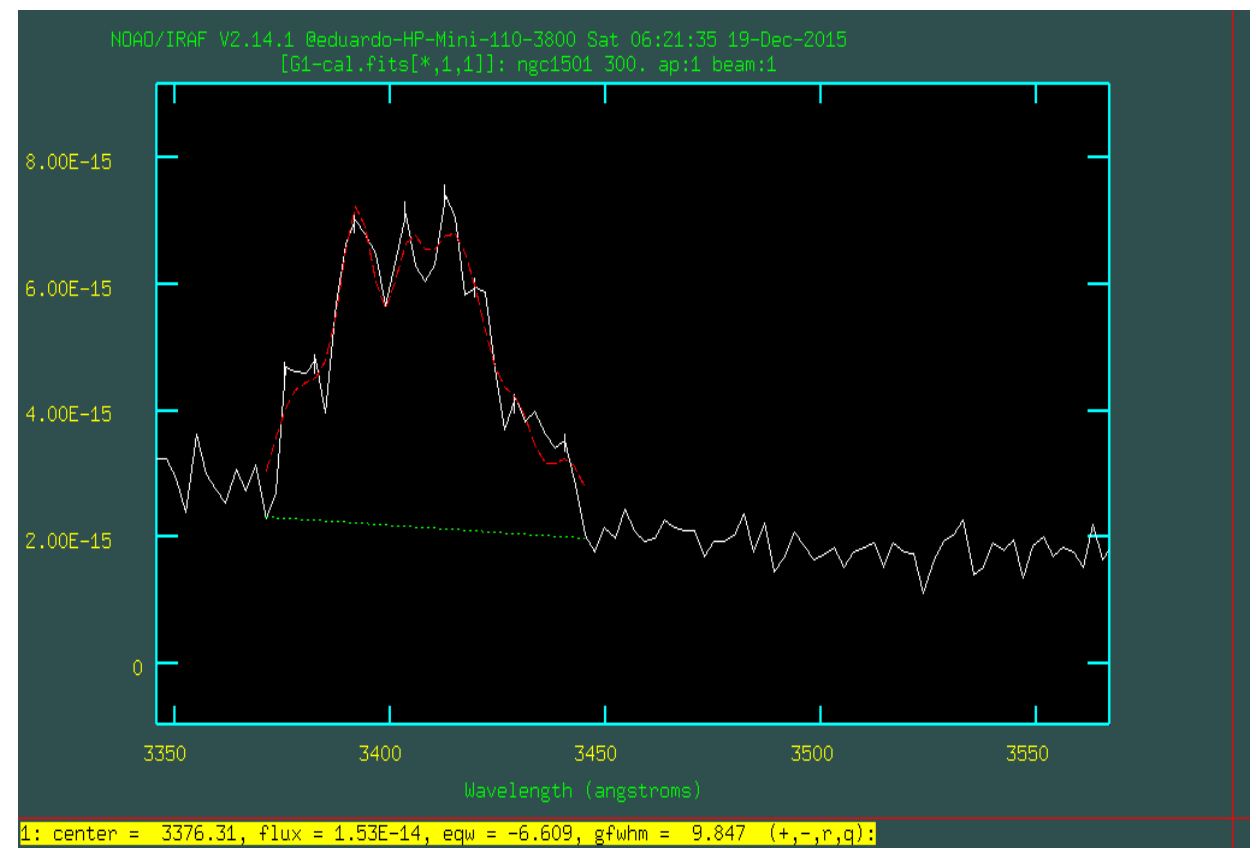

Figura 12: Deblending aplicado a las líneas 1 al 8 de la tabla 1.

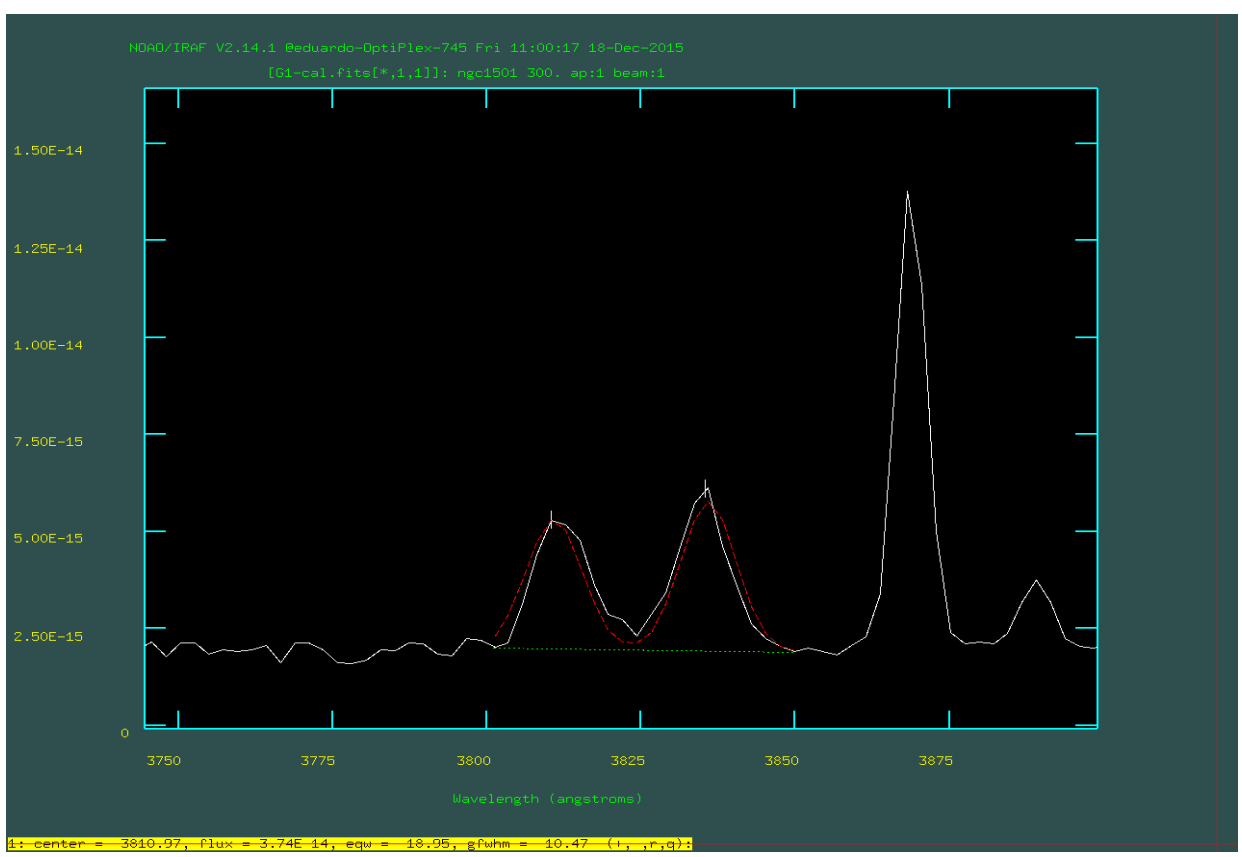

Figura 13: Deblending aplicado a las líneas 12 al 13 de la tabla 1.

Previo a la identificación de las líneas de emisión, se deben descartar aquellas que no se pueden diferenciar del ruido de fondo. Esto es debido a que sus flujos de energía son muy pequeños, así que estadísticamente no se pueden diferenciar el ruido de fondo del continuo de luz. El procedimiento seguido para seleccionar 
las líneas a eliminar fue el siguiente:

- Se calculó el valor promedio de la radiación del continuo, $\mu$, a partir de los valores que tenía en cada línea de emisión estudiada (si estaba disponible y se muestran los valores obtenidos en la cuarta columna de la tabla 1). El valor promedio obtenido fue de $0.15683 \mathrm{erg} \mathrm{cm}^{-2} \mathrm{~s}^{-1}$.

- Se calculó la desviación estándar $\sigma$ para esta muestra de valores del continuo. El valor obtenido fue de 0.05792 .

- Se calculó el intervalo de confianza en el que podremos encontrar todo el ruido, con un $99 \%$ de confianza. Es decir:

$$
\mu-Z_{99 \%} \sigma<\text { Ruido }<\mu+Z_{99 \%} \sigma
$$

donde $Z=2.33$ es el factor estadístico para la probabilidad deseada, para una distribución normal (Wackerly et al., 2002).

En este caso, nos interesa únicamente el límite superior del ruido de fondo (R.F.), ya que estamos eliminando líneas de emisión, por tanto, se eliminarán las líneas cuyo valor sea inferior a:

$$
\begin{aligned}
\text { Límite superior R.F } & =\mu+Z_{99 \%} \sigma \\
& =0.15683+2.33 \times 0.05796 \\
& =0.2919
\end{aligned}
$$

Así, toda línea con un flujo menor o igual a $0.2919 \times 10^{-14} \mathrm{erg} \mathrm{cm}^{-2} \mathrm{~s}^{-1}$ fue descartada, lo que sucede para las líneas 16, 20, 21 y 22 de la tabla 1. Las líneas 35, 36, 37 y 38 no se descartaron, ya que se puede observar que el valor del continuo a estas longitudes de onda es muy bajo (ver línea 37, donde el continuo tiene un valor de $0.00281 \mathrm{erg} \mathrm{cm}^{-2} \mathrm{~s}^{-1}$ ) y entonces no se pueden descartar los flujos de las líneas alrededor de la línea 37.

Para la identificación de las líneas de emisión, se utilizó como herramienta el servicio del Instituto Nacional de Normas y Tecnología (NIST, por sus siglas en inglés), que está disponible en el sitio. Web: http://physics.nist.gov/PhysRefData/ASD/lines_form.html, como se puede apreciar en la figura 14 de (Kramida et al., 2015). Las líneas ya identificadas se presentan en la tabla 2.

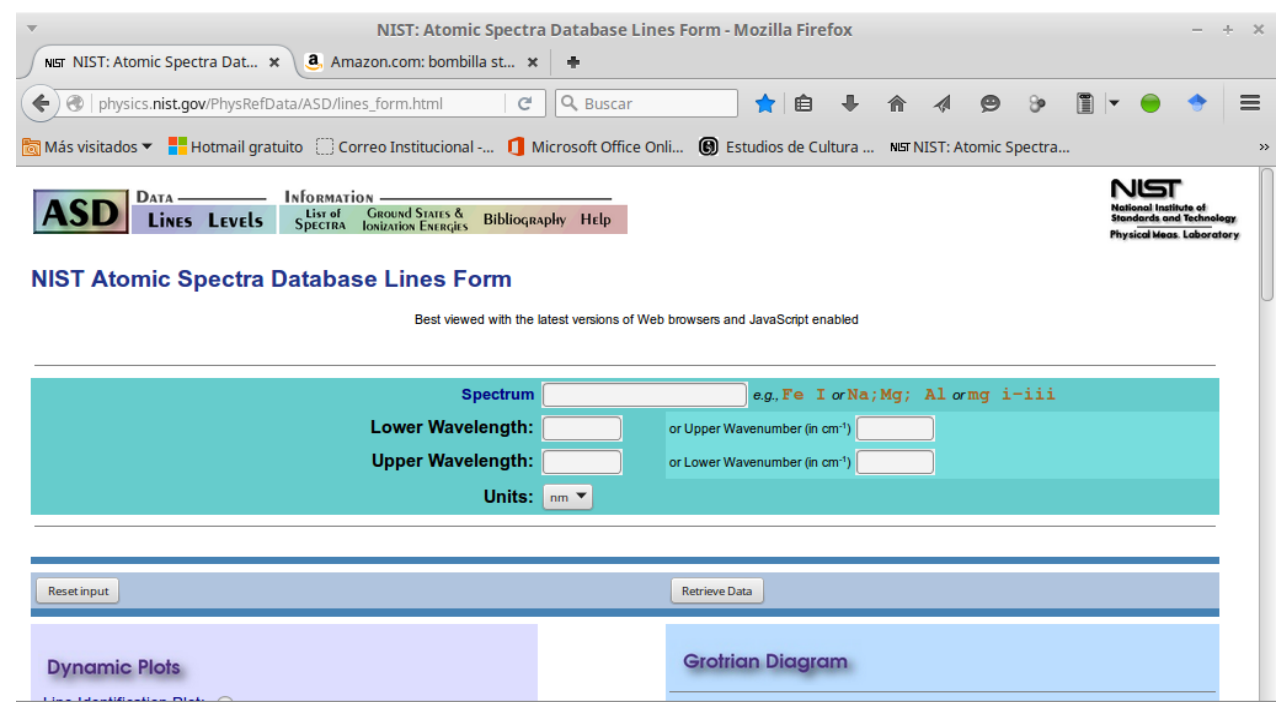

Figura 14: Sito web del NIST que da acceso al servicio de identificación de líneas de emisión. 
A pesar de haber una gran cantidad de líneas de emisión en el espectro bajo estudio, no se encontraron líneas en la base de datos que coincidieran perfectamente en el valor de la longitud de onda. Por este motivo se seleccionaron de la herramienta del NIST las líneas de los elementos más comunes del universo que estuvieran más cercanos a la longitud de onda observada. Así, se encontró que hay una gran cantidad de líneas del oxígeno, del hidrógeno (serie de Balmer), helio y carbono y sólo un par de líneas correspondientes al Nitrógeno cuatro veces ionizado (N V).

Tabla 2: Identificación propuesta de algunas de las líneas presentes en el espectro de NGC 1501

\begin{tabular}{|c|c|c|c|c|c|c|}
\hline $\mathrm{N}^{\circ}$ & $\begin{array}{c}\text { Longitud de onda } \\
\AA\end{array}$ & $\begin{array}{l}\text { Flujo } \times 10^{14} \\
\text { erg } \mathrm{cm}^{-2} \mathrm{~s}^{-2}\end{array}$ & $\begin{array}{l}\text { Continuo } \times 10^{14} \\
\text { erg } \mathrm{cm}^{-2} \mathrm{~s}^{-2}\end{array}$ & $\begin{array}{c}\text { Ancho equivalente }{ }^{* *} \\
(\AA)\end{array}$ & Observaciones & ID \\
\hline 1 & 3376.310 & 1.53 & & 6.609 & Deblending* & O III \\
\hline 2 & 3383.280 & 1.54 & & 6.765 & Deblending* & O III \\
\hline 3 & 3404.230 & 4.37 & & 19.97 & Deblending* & O IV \\
\hline 4 & 3413.440 & 3.85 & & 17.97 & Deblending* & O IV \\
\hline 5 & 3420.420 & 2.67 & & 12.63 & Deblending* & O II \\
\hline 6 & 3429.630 & 1.92 & & 9.271 & Deblending* & [O III] \\
\hline 7 & 3441.350 & 1.25 & & 6.212 & Deblending* & N V \\
\hline 8 & 3690.433 & 1.114 & 0.1868 & 5.6723 & & $\mathrm{OV}$ \\
\hline 9 & 3727.177 & 1.085 & 0.2018 & 5.3744 & & O II \\
\hline 10 & 3810.970 & 3.74 & & 18.95 & Deblending* & O III \\
\hline 11 & 3835.940 & 4.36 & & 22.77 & Deblending* & O II \\
\hline 12 & 3868.731 & 7.707 & 0.1962 & 39.0232 & & O IV \\
\hline 13 & 3889.090 & 1.047 & 0.2043 & 5.1249 & & $\mathrm{H}_{\varepsilon}$ \\
\hline 14 & 3936.340 & 0.449 & & 2.525 & & He I \\
\hline 15 & 3944.580 & 0.403 & & 2.236 & & O III \\
\hline 16 & 4101.750 & 2.003 & 0.1747 & 11.5112 & & $\mathrm{H}_{\delta}$ \\
\hline 17 & 4340.132 & 2.93 & 0.1252 & 23.5409 & & $\mathrm{H}_{\gamma}$ \\
\hline 18 & 4658.980 & 7.26 & & 43.55 & Deblending* & C III \\
\hline 19 & 4361.601 & 0.7775 & 0.1283 & 48.94 & & [O III] \\
\hline 20 & 4686.030 & 6.12 & & 90.52 & Deblending* & He II \\
\hline 21 & 4861.344 & 14.84 & 0.132 & 75.6657 & & $\mathrm{H}_{\beta}$ \\
\hline 22 & 4958.994 & 58.42 & 0.236 & 246.793 & & [O III] \\
\hline 23 & 5006.945 & 181.9 & 0.167 & 1087.499 & & [O III] \\
\hline 24 & 6548.620 & 0.786 & & 134 & Deblending* & [N II] \\
\hline 25 & 6563.550 & 70.10 & & 12000 & Deblending* & $\mathrm{H}_{\alpha}$ \\
\hline 26 & 6716.360 & 0.0155 & & 5.387 & & [S II] \\
\hline 27 & 6730.800 & 0.0181 & & 6.184 & & [S II] \\
\hline 28 & 6803.511 & 0.06179 & 0.00281 & 26.6705 & & Fe I \\
\hline 29 & 6907.750 & 0.0347 & & 10.08 & Deblending* & Fe II \\
\hline 30 & 6936.290 & 0.517 & & 143.1 & & O II \\
\hline $\begin{array}{l}{ }^{*} \mathrm{Fu} \\
\text { esta } \\
{ }^{*} \mathrm{Tc}\end{array}$ & $\begin{array}{l}\text { necesario ejecutar } \\
\text { íneas, que en un } \\
\text { os los valores del }\end{array}$ & módulo de " & blending" en el & $\begin{array}{l}\text { tware IRAF para po } \\
\text { hea de emisión muy } \\
-1\end{array}$ & $\begin{array}{l}\text { r diferenciar } \\
\text { cha }\end{array}$ & \\
\hline
\end{tabular}

El elemento para el que se encontró una gran cantidad de líneas de emisión es el oxígeno, con 15 líneas:

- una vez ionizado (O II): 4 líneas (filas 5, 9, 11 y 30 de la tabla 2)

- dos veces ionizado (O III): 7 líneas (filas 1, 2, 6, 10, 15, 22 y 23 de la tabla 2)

- tres veces ionizado (O IV): 3 líneas (filas 3, 4 y 12 de la tabla 2)

- cuatro veces ionizado (O V): 1 línea (fila 8 de la tabla 2)

El siguiente elemento con más líneas de emisión es el hidrógeno, con 5 líneas: las líneas de Balmer desde la $\alpha$ hasta la $\varepsilon$ (filas 13,16, 17, 21 y 25). Más allá de estas líneas no se identifican otras relacionadas con 
este elemento. La intensidad relativa (respecto a la línea $\mathrm{H}_{\varepsilon}$ ) de estas líneas es de 66.9, 14.2, 2.8,1.9 y 1.0, respectivamente.

Se identifican otros elementos tales como:

- Nitrógeno 4 veces ionizado (N V): 2 líneas (filas 7 y 24 de la tabla 2)

- Azufre una vez ionizado (S II): 2 líneas (filas 26 y 27 de la tabla 2)

- Hierro, tanto ionizado una vez como neutro (filas 28 y 29 de la tabla 2)

- Helio, sin ionizar (He I) y una vez ionizado (He II): 1 línea cada uno (filas 14 y 20 de la tabla 2, respectivamente)

Dado que el objetivo del presente trabajo es caracterizar la nebulosa NGC 1501 respecto a tres parámetros: densidad de polvo interestelar en la línea de visión Tierra-nebulosa, temperatura electrónica y densidad electrónica de la nebulosa, concentramos nuestra atención en las líneas del espectro que normalmente se utilizan para el diagnóstico de estas propiedades:

- Relación entre las líneas de Balmer del hidrógeno: Enrojecimiento por gas y polvo interestelar

- Relación de las líneas de azufre una vez ionizado [S II]: Densidad electrónica

- Relación entre líneas de oxígeno doblemente ionizado [O III]: temperatura electrónica

\section{Cálculo de la cantidad de polvo interestelar en la línea de visión Tierra-NGC 1501}

La determinación de la cantidad de enrojecimiento interestelar en la línea de visión Tierra-nebulosa es muy útil porque servirá para realizar correcciones en los flujos de las líneas de emisión, que son más afectadas cuanto menor sea su longitud de onda. Se utilizan para esto las líneas de Balmer del hidrógeno $\alpha$ y $\beta$. Se sabe que la relación del flujo de energía de la línea de emisión alfa respecto de la línea de emisión beta (transición desde un orbital con $n=4$ a uno con $n=2$ ) es, para pruebas de laboratorio, de 2.87 (Osterbrock y Ferland, 2006). En el caso de NGC 1501, se encuentra que para los flujos observados $\left(F_{0}\right)$ de cada línea existe una relación de tal forma que:

$$
\begin{aligned}
\text { Relación de flujos } & =\frac{F_{0}\left[\mathrm{H}_{\alpha}\right]}{F_{0}\left[\mathrm{H}_{\beta}\right]} \\
& =\frac{70.10 \times 10^{-14}}{14.84 \times 10^{-14}} \\
& =4.7
\end{aligned}
$$

Es decir, la línea $\mathrm{H}_{\beta}$ es mucho menos brillante respecto a la $\mathrm{H}_{\alpha}$ para el objeto NGC 1501 que en el caso del laboratorio, por tanto, hay enrojecimiento provocado por la extinción interestelar. Se puede calcular la cantidad de polvo interestelar que oscurece el flujo de energía recibido, utilizando la siguiente ecuación, obtenida a partir de la ecuación (7.6) y la ley de enrojecimiento "estándar", ambas descritas en (Osterbrock y Ferland, 2006):

$$
\frac{I_{\lambda 1}}{I_{\lambda 2}}=\frac{I_{\lambda 10}}{I_{\lambda 20}} e^{-C\left[f\left(\lambda_{1}\right)-f\left(\lambda_{2}\right)\right]}
$$


Pero sabemos que $c=0.434 C$ y que, por la ley "estándar" de enrojecimiento, el exceso de color E(B$\mathrm{V}) \sim 0.77 c$ (Osterbrock y Ferland, 2006). Combinando estas ecuaciones y sustituyendo en la ecuación 4.8, se obtiene que:

$$
\frac{I_{\lambda 1}}{I_{\lambda 2}}=\frac{I_{\lambda 10}}{I_{\lambda 20}} e^{-2.9924 E[B-V]\left[f\left(\lambda_{1}\right)-f\left(\lambda_{2}\right)\right]}
$$

La relación entre intensidades para un mismo objeto es la misma que las intensidades del flujo detectado, por tanto, ya se conoce el término de la izquierda, que tiene un valor de 4.7. La relación de intensidades en el término derecho (correspondiente a los valores experimentales en laboratorio) también se conoce y tiene un valor de 2.87. Los valores para $f\left(\lambda_{i}\right)$ (donde i sirve para identificar la línea de emisión que nos interesa) se obtienen a partir de las curvas de extinción medidas para objetos en la Vía Láctea. Con ayuda de la tabla 1 de (Osterbrock y Ferland, 2006), $f\left(\lambda \mathrm{H}_{\alpha}\right)=0.818$ mientras para $f\left(\lambda \mathrm{H}_{\beta}\right)=1.164$. Así, solo queda por determinar el valor de $\mathrm{E}[\mathrm{B}-\mathrm{V}]$, con el que luego se calcula la extinción causada por gas y polvo interestelar. Al hacer las sustituciones respectivas y despejando para $\mathrm{E}[\mathrm{B}-\mathrm{V}]$, se encuentra que este parámetro tiene un valor de 0.4797 .

Utilizando la tabla 3 en (Fitzpatrick, 1999) para obtener el valor del coeficiente de absorción $A(\lambda)$, interpolando obtenemos que:

$$
\begin{aligned}
\frac{A\left(\mathrm{H}_{\alpha}\right)}{E(B-V)} & =2.519 \\
A\left(\mathrm{H}_{\alpha}\right) & =2.519 \times 0.4797 \\
A\left(\mathrm{H}_{\alpha}\right) & =1.21 \\
A\left(\mathrm{H}_{\alpha}\right) & =\text { extinción total en la longitud de onda de } \mathrm{H}_{\alpha}
\end{aligned}
$$

Utilizando la teoría de Mie, como descrito en (Carroll y Ostlie, 2007), asumiendo un coeficiente de extinción de Mie $\mathrm{Q}_{\mathrm{H} \alpha}=1.5$ (relación entre área transversal de dispersión respecto del área transversal de la partícula promedio en la línea de visión), y partículas de radio $a=0.2 \mu \mathrm{m}$, se obtiene que:

$$
\begin{gathered}
\tau_{\mathrm{H}_{\alpha}}=\frac{A_{\mathrm{H}_{\alpha}}}{1.086}=1.11 \\
\sigma_{\mathrm{H}_{\alpha}}=\pi \times a^{2} \times Q_{\mathrm{H}_{\alpha}}=2 \times 10^{-13} \mathrm{~m}^{2}
\end{gathered}
$$

La densidad por área de la columna de polvo en la línea de visión es:

$$
N_{d}=\frac{\tau_{\mathrm{H}_{\alpha}}}{\sigma_{\mathrm{H}_{\alpha}}}=\frac{1.11}{2 \times 10^{-13}}=5.55 \times 10^{12} \mathrm{~m}^{-2}
$$

Conociendo que la distancia a NGC 1501 es de aproximadamente $1.3 \mathrm{kpc}$ (Sabbadin et al., 2000), se calcula una densidad volumétrica de polvo en la línea de visión así:

$$
\bar{n}=\frac{N_{d}}{\text { Distancia }}=\frac{5.55 \times 10^{12} \mathrm{~m}^{2}}{1.3 \mathrm{kpc}}=\frac{5.55 \times 10^{12} \mathrm{~m}^{-2}}{4.01 \times 10^{19} \mathrm{~m}}=1.38 \times 10^{-7} \mathrm{~m}^{-3}
$$

\section{Cálculo de la intensidad electrónica en la nebulosa NGC 1501}

En el cálculo de esta propiedad, se utilizan normalmente las líneas de emisión del elemento oxígeno una vez ionizado [OII] o azufre una vez ionizado [SII], presentes en el medio bajo estudio (Osterbrock y Ferland, 2006). En nuestro caso, se detectaron en el espectro las líneas de emisión del [SII], por tanto, se les utilizará para lograr el objetivo de encontrar la densidad electrónica (ver figura 15). 
Las líneas utilizadas fueron la de $6716 \AA$ y $6731 \AA$, que tienen una diferencia en su longitud de onda los suficientemente grande como para permitir su diferenciación al revisar el espectro. En la tabla 2, estas líneas se corresponden con las de los renglones 26 y 27. Estas líneas se corrigen por el efecto de la extinción utilizando la relación $A(\lambda)=$ Factor $\times E(B-V)$ para $R=3.1$ según la ley estándar de enrojecimiento para objetos en la Vía Láctea. El factor se calcula utilizando la tabla 3 en (Fitzpatrick, 1999), según la longitud de onda bajo estudio, obteniendo así el flujo de energía con que se debe trabajar, como se muestra en la tabla 3.
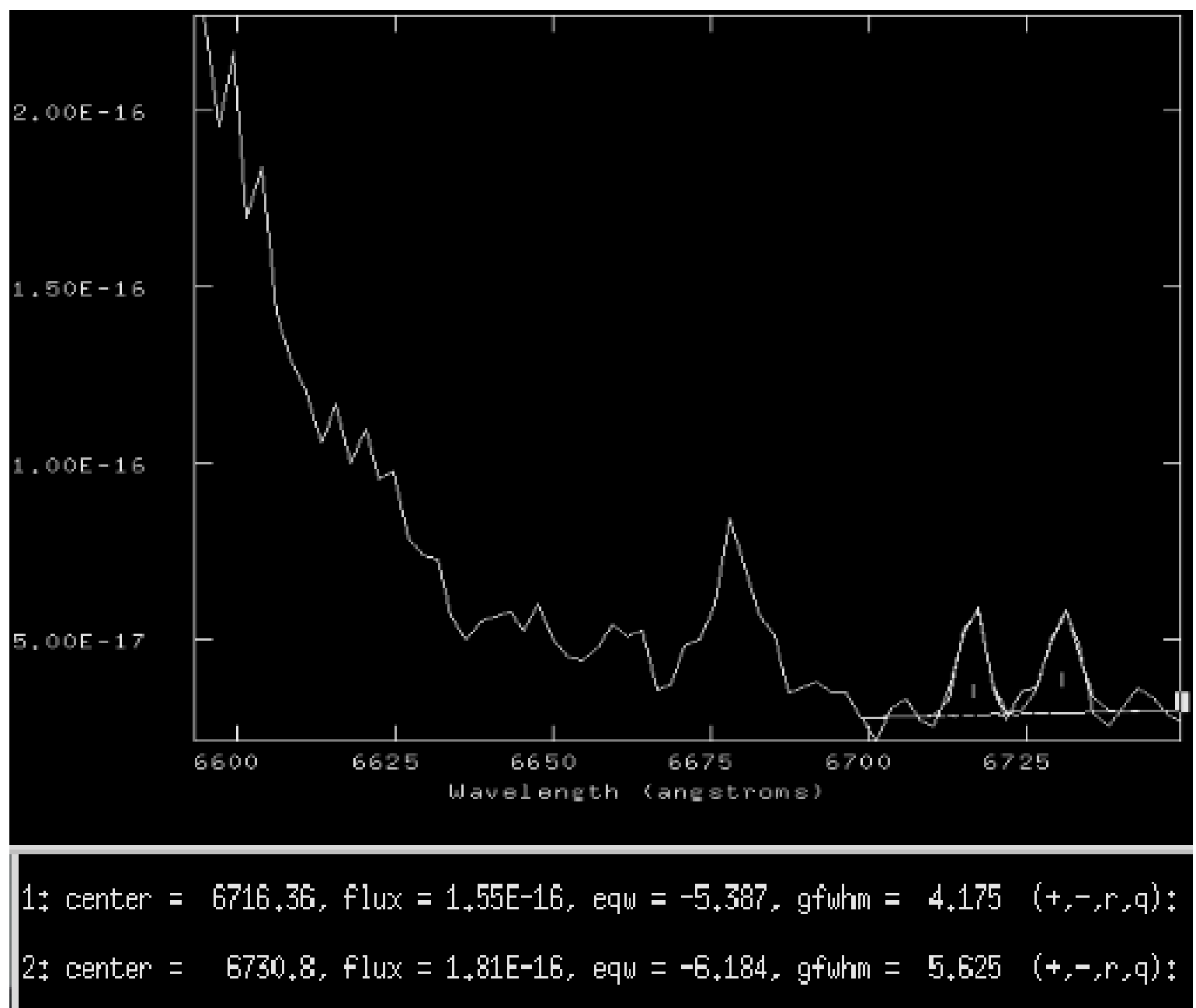

Figura 15: Líneas de emisión del [SII] de la nebulosa NGC 1501.

Tabla 3: Líneas de emisión del [S II] corregidas por extinción

\begin{tabular}{cccccc}
\hline $\mathrm{N}^{\circ}$ & $\begin{array}{c}\text { Longitud de onda } \\
(\AA)\end{array}$ & $\begin{array}{c}\text { Flujo } \\
\left(10^{-14} \mathrm{erg} \mathrm{cm}^{-2} \mathrm{~s}^{-2}\right)\end{array}$ & $\begin{array}{c}A(\lambda) \\
\left(10^{-14} \mathrm{erg} \mathrm{cm}^{-2} \mathrm{~s}^{-2}\right)\end{array}$ & $\begin{array}{c}\text { Flujo corregido } \\
\left(10^{-14} \mathrm{erg} \mathrm{cm}^{-2} \mathrm{~s}^{-2}\right)\end{array}$ & ID \\
\hline 1 & 6716.36 & 0.0155 & 1.186 & 1.202 & [S II] \\
2 & 6730.80 & 0.0181 & 1.184 & 1.202 & [S II] \\
\hline
\end{tabular}

Como se observa, los valores corregidos son iguales. Al revisar la figura 5.8 de (Osterbrock y Ferland, 2006), se encuentra que para esta relación de 1 , a una temperatura de $10^{4} \mathrm{~K}$, la densidad electrónica de la nebulosa debería ser $500 \mathrm{~cm}^{-3}$. 


\section{Cálculo de la temperatura electrónica de NGC 1501}

Para calcular este parámetro, se hace uso de las líneas prohibidas de emisión del oxígeno dos veces ionizado, tal como se define en la literatura. Las líneas que se utilizaron fueron la de $5007 \AA$, $4959 \AA$ y 4363 $\AA$, que se identifican en la tabla 2 en los renglones 23,22 y 19, respectivamente. Estas líneas también se corrigen por el efecto de la extinción para obtener el flujo de energía con que se debe trabajar, como se muestra en la tabla 4.

Tabla 4: Líneas de emisión del [O III] corregidas por extinción

\begin{tabular}{cccccc}
\hline $\mathrm{N}^{\circ}$ & $\begin{array}{c}\text { Longitud de onda } \\
(\AA)\end{array}$ & $\begin{array}{c}\text { Flux } \\
\left(10^{-14} \mathrm{Erg} \mathrm{cm}^{-2} \mathrm{~s}^{-2}\right)\end{array}$ & $\begin{array}{c}A(\lambda) \\
\left(10^{-14} \mathrm{Erg} \mathrm{cm}^{-2} \mathrm{~s}^{-2}\right)\end{array}$ & $\begin{array}{c}\text { Flux Corregido } \\
\left(10^{-14} \mathrm{Erg} \mathrm{cm}^{-2} \mathrm{~s}^{-2}\right)\end{array}$ & ID \\
\hline 1 & $4363\left(4361.6^{*}\right)$ & 0.7775 & 1.963 & 2.740 & [O III] \\
2 & 4959 & 58.42 & 1.695 & 60.12 & [O III] \\
3 & 5007 & 181.9 & 1.674 & 183.6 & [O III] \\
\hline \multicolumn{7}{r}{ *Valor medido en este trabajo } \\
\hline
\end{tabular}

Utilizando los valores de la quinta columna, se aplica la relación de flujos:

$$
\text { Relación de flujos }=\frac{j_{\lambda 4959}+j_{\lambda 5007}}{j_{\lambda 4363}}=\frac{60.12+183.6}{2.740}=88.9
$$

Conociendo este dato y asumiendo una densidad electrónica $\left(n_{e}=1 \mathrm{~cm}^{-3}\right)$, se puede utilizar la figura 5.1 en (Osterbrock y Ferland, 2006), obtenida a partir de la ecuación 5.4 en la misma referencia, resultando un valor de Temperatura electrónica de $1.35 \times 10^{4} \mathrm{~K}$. Sin embargo, dado que anteriormente se encontró que la densidad electrónica en la nebulosa es de $500 \mathrm{~cm}^{-3}$, se repite nuevamente el cálculo usando únicamente la ecuación 5.4 antes mencionada, obteniendo que $T_{e}=1.36 \times 10^{4} \mathrm{~K}$. Estos valores están dentro del mismo orden de magnitud y en concordancia con los valores hallados en (Sabbadin et al., 2000) que da un valor de $1.15 \times 10^{4} \pm 500 \mathrm{~K}$ y (Stanghellini et al., 1994), que reportó $1.07 \times 10^{4} \mathrm{~K}$. Las diferencias pueden deberse a variaciones locales dentro de la nebulosa, que no son completamente abarcadas al realizar la toma de espectros con rendijas finas.

\section{Relación entre densidad electrónica y temperatura electrónica}

Según se deduce de las leyes de los gases, existe una relación directa entre densidad de materia y temperaturas. Por tanto, los valores de densidad y temperatura electrónica hallados de forma independiente deben ser corregidos desde las condiciones estándar en que se calcularon, para que ambos valores sean los que corresponden a las condiciones reales en la nebulosa.

En una primera aproximación se encontró que la densidad electrónica dentro de la nebulosa es de $500 \mathrm{~cm}^{-3}$, pero como resultado de haber asumido una temperatura de $10^{4} \mathrm{~K}$ para utilizar las tablas en las referencias. Al corregir según el método en la figura 5.8 de (Osterbrock y Ferland, 2006) para la nueva temperatura calculada, que es de $1.36 \times 10^{4} \mathrm{~K}$, se encuentra ahora que la densidad debería ser $430 \mathrm{~cm}^{-3}$. Comparando con las referencias, se observa que los valores publicados varían, siendo el máximo encontrado de $1480 \mathrm{~cm}^{-3}$ (Stanghellini et al., 1994), luego $10^{3} \mathrm{~cm}^{-3}$ (Ercolano et al., 2004) y según la orientación espacial hacia donde se está tomando el espectro, la densidad varía de 0 a $10^{3}$ (Sabbadin et al., 2000). Las variaciones en la última referencia se deben principalmente al ángulo de posición de la rendija utilizada.

Con el nuevo valor de densidad se realiza una nueva corrección en la temperatura utilizando nuevamente la ecuación 5.4 de (Osterbrock y Ferland, 2006), obteniendo prácticamente el mismo resultado de $1.36 \times 10^{4}$ K. 


\section{Conclusiones}

Los objetivos planteados al inicio del trabajo fueron alcanzados, dado que se obtuvieron algunos datos que caracterizan a la nebulosa planetaria NGC1501 y su entorno. Se identificaron numerosos elementos que se presentan en este tipo de objetos:

- Oxígeno en múltiples etapas de ionización, que concuerda con una fuente de excitación que debería emitir en el ultravioleta para obtener los iones observados. Las líneas de emisión observadas para este ion se corresponden con líneas de emisión al ocurrir saltos entre orbitales cuya probabilidad de que ocurran es muy baja, es decir, son líneas prohibidas, lo que permite inferir la baja densidad de material en la nebulosa, por tanto, volviendo aplicables los métodos de caracterización de objetos astronómicos desarrollados para estos casos.

- Hidrógeno, del que se identificaron las líneas de la serie de Balmer, que al ser analizados en cuanto a sus relaciones de flujo, han servido para comprobar la presencia de polvo interestelar entre el objeto y la Tierra.

- Nitrógeno altamente ionizado, que ocurre en presencia de una fuente de radiación ionizante intensa, como el que debería existir en el entorno de estrellas enanas blancas.

- Helio, que se encuentra en los estados neutro y una vez ionizado. Esto pone un límite a la cantidad de radiación UV disponible para la completa ionización del helio presente.

Por otro lado, el análisis de las líneas de emisión del hidrógeno $\mathrm{H}_{\alpha} \mathrm{y} \mathrm{H}_{\beta}$ permitió obtener un estimado de la cantidad de polvo en la línea de visión Tierra-nebulosa, que queda evidenciado por el exceso de color $\mathrm{E}(\mathrm{B}-\mathrm{V})$ que se encuentra en la relación entre dichas líneas. Se encontró que este polvo tiene una densidad volumétrica de $1.38 \times 10^{-7} \mathrm{~m}^{-3}$, dato que puede servir como punto de partida para posteriores análisis tanto de este objeto como de otros presentes en la vecindad, siempre y cuando la distancia sea muy similar a la de NGC 1501. Al compararse el resultado obtenido de densidad electrónica $\left(n_{e}=430 \mathrm{~cm}^{-3}\right)$ con el que es típico de nebulosas planetarias, entre 100 y $10^{4} \mathrm{~cm}^{-3}$ (Osterbrock y Ferland, 2006), se encuentra que el mismo se encuentra dentro del rango inferior normal para dichos cuerpos astronómicos. La temperatura electrónica $\left(T_{e}=1.36 \times 10^{4} \mathrm{~K}\right)$ está en el rango superior para valores típicos de nebulosas planetarias.

\section{Agradecimientos}

Agradecemos las valiosas observaciones hechas por el máster Alejandro Saravia, las que ayudaron mejorar la presentación y a aclarar algunas de las ideas aquí plasmadas. 


\section{Referencias}

Carroll, B. W. y Ostlie, D. A. (2007). An introduction to modern astrophysics; 2 nd ed. Addison-Wesley, San Francisco, CA.

Ercolano, B., Wesson, R., Zhang, Y., Barlow, M. J., De Marco, O., Rauch, T., y Liu, X. (2004). Observations and three-dimensional photoionization modelling of the Wolf-Rayet planetary nebula NGC 1501. Monthly Notices of the Royal Astronomical Society, 354(2):558-574.

Fitzpatrick, E. (1999). Correcting for the effects of interstellar extinction. Publications of the Astronomical Society of the Pacific, 111:63-75.

Fritz, J. (2015). Notes of "astronomical spectroscopy". en prensa. material de apoyo para la Asignatura "Espectroscopía", Tegucigalpa, Honduras: UNAH, Maestría Académica Regional en Astronomía y Astrofísica.

Kramida, A., Ralchenko, Y., Reader, J., y 2015, N. A. T. (2015). Nist atomic spectra database (ver. 5.3). urlhttp://physics.nist.gov/asd.

Osterbrock, D. y Ferland, G. (2006). The Astrophysics of Gaseous Nebulae and Active Galactic Nuclei. University Science Books, 2nd. ed.

Sabbadin, F., Benetti, S., Cappellaro, E., y Turatto, M. (2000). The tetra-lobed planetary nebula NGC 1501. Astronomy and Astrophysics, 361:1112-1120.

Stanghellini, L., Kaler, J., y Shaw, R. (1994). Narrow emission line O VI planetary nebulae nuclei. Astronomy and Astrophysics, 291:604-612.

Tody, D. (1986). The IRAF Data Reduction and Analysis System. En Crawford, D. L., editor, Instrumentation in astronomy VI, volumen 627 de Proceedings of SPIE, p. 733.

Wackerly, D., Mendenhall, W., y Scheaffer, R. (2002). Estadística matemática con aplicaciones. Grupo Editorial Iberoamérica. 